\title{
Collaborative Learning: Patterns of Student Perceptions of the Contributions of Other Team Members During a Group Project
}

\author{
Robert Maribe Branch \\ University of Georgia \\ Hyewon Lee \\ University of Georgia
}

\begin{abstract}
This paper reports the results of student perceptions about the individual contributions of group members that participated in a team assignment as part of a tertiary education course. The practice of designing coursework with group projects needs to adhere to Johnson, Johnson and Smith's (2006) strategies for [cooperative] learning in college classrooms, who emphasize creating interdependence, devoting time for developing teamwork skills, and cultivating an atmosphere of individual accountability. The significance is the importance of students having the opportunity to express their perceptions about ways that other members affect their own score for a class assignment.
\end{abstract}

Keywords: teamwork, group work, projects, learning, design, collaboration

\section{INTRODUCTION}

This study reports the results of students' perceptions regarding the individual contributions of group members who participated in a team project as part of a tertiary education course. While there were several individual assignments throughout the course, the team project was the culminating activity. The rationale for assigning group projects in tertiary education courses is to promote successful teamwork. Tarricone and Luca (2002) identified six attributes needed for effective teamwork:

1. Commitment to team success and shared goals

2. Interdependence

3. Interpersonal skills

4. Open communication and positive feedback

5. Appropriate team composition

6. Commitment to team processes, leadership \& accountability (p. 641)

The practice of designing coursework with team projects is also consistent with Johnson, Johnson, and Smith's (2006) strategies for [cooperative] learning in college classrooms. Johnson et al. emphasize a) creating interdependence, b) devoting time for developing teamwork skills, and c) cultivating an atmosphere of individual accountability. The course in which the data was collected adhered to all three components of the cooperative learning in college classrooms strategy. The students were introduced to 
the notion of working as a team through content provided throughout the course, particularly introducing the idea using a quote from Adams and Dickey (1953): "The group process depends upon the thinking, planning, deciding, and acting together of the members of the group. The end product is accomplishment, which an individual working alone could not effect. To achieve the goal, full use must be made of the ideas and experiences of the group members as they interact with each other. The interdependence of behavior unifies the group and provides the driving force and power for the action in progress. All members of the group may initiate problems, suggests proposals, or take action to promote cooperatively determined plans. The action of individuals to achieve common goals becomes unified and integrated by belief in those ideals and by performing those activities, which the group itself has determined. Authority then, is not a function of position or the prerogative of an individual; it resides in the group."

Figure 1 is an excerpt from the course syllabus that describes for the students the purpose of the group project. The significance is the importance of students having the opportunity to express their perceptions about ways that other members affect their own score for a class assignment.

\section{FIGURE 1 \\ DIRECTIONS FOR THE GROUP PROJECT (AS PER THE COURSE SYLLABUS)}

\section{Proposal [Team Project]}

The purpose of constructing a Learning Proposal is to simulate authentic instructional design. Preparing a Proposal simulates the roles and responsibilities of an instructional designer. The goal is to plan an intervention for a performance discrepancy attributable to a lack of knowledge and skills. The Learning Proposal is a detailed document for developing a course of study. The Proposal is both descriptive and prescriptive. There are two phases in developing the Proposal. The first phase leads to an Analysis Summary. The second phase leads to a Complete Proposal. The Proposal is a team project constructed through small-group activities and based on a systematic process. While time will be set aside during class for design team meetings, students are expected to meet as a design team outside of class. The course schedule has been arranged to accommodate these outside-of-class design team meetings. Each student is required to work within a design team.

\section{Problem}

The problem is that students unaccustomed to working with others on projects with genuine consequences often fail to equally contribute to the group. While college instructors realize the value of group projects as a way to augment individual assignments during academic study, teamwork poses a unique set of issues. A common consequence of inequitable participation among individual team members is the poor performance of the entire group.

\section{Conceptual Framework}

This study adopted the conceptual framework of an intentional learning space (Branch \& Chae, 2016) as presented in Figure 2. The premise is based on one instructor's desire to emulate the reality outside his classroom within the dedicated space inside the classroom.

Miles, Hubert, and Saldana (2014) point out the role of a conceptual framework as depicting the visual explanation of the main variables and presumed relationships in a study. Further, effort is treated differently from actual contribution because the amount of effort for the contribution of one individual can vary significantly compared to another individual with the same degree of contribution with a substantially different amount of effort. Therefore, this study focused on patterns of agreement among group members while completing a team academic assignment. The idea is to measure the perceived degree of the contributions of other team members by every individual team member. 
FIGURE 2

\section{INTENTIONAL LEARNING SPACE}

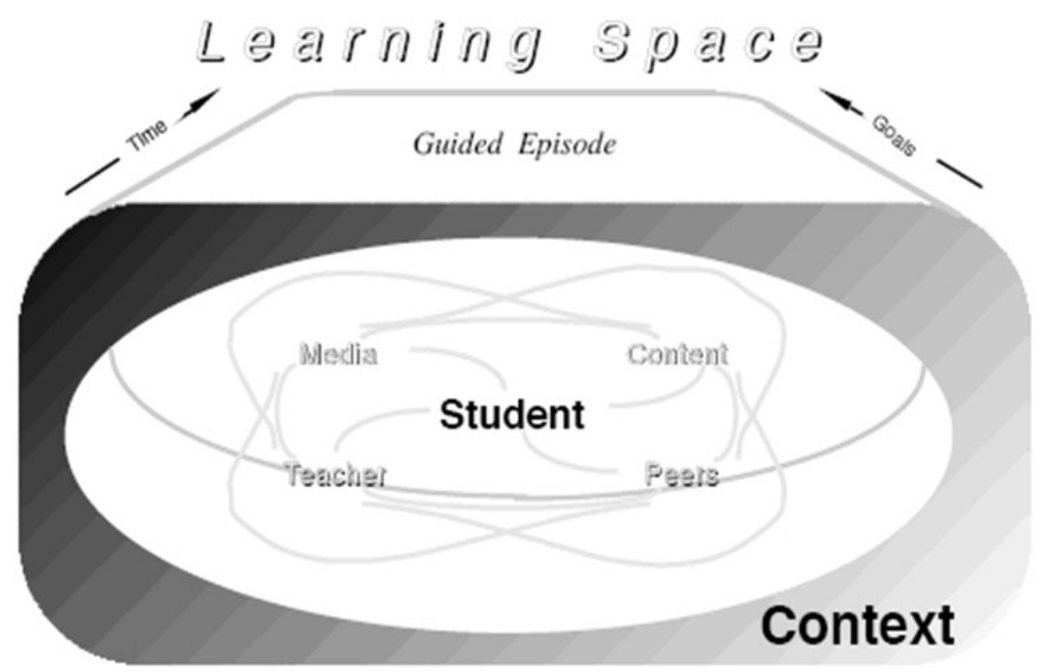

\section{Research Questions}

There were delimitations to this study [or self-imposed limits for keeping the study manageable], such as only collecting data from courses taught by the same instructor and only using data from a course on the same subject. The following questions were used to guide this study:

1. What percent had an equal distribution?

2. What percent had a small distribution?

3. What was the range of the distribution of scores in the teams exhibiting a large distribution?

\section{RESEARCH DESIGN}

\section{Participants}

The participants were students enrolled in a tertiary education course offered at a large public university in the southeastern United States.

\section{Context}

The course has been offered in the fall semester almost every year, with the exception of a couple of years, and instructed by the same instructor, one of the researchers for this study, since 2006. The students were expected to achieve the same learning outcomes that accompany each goal over this period. Although the details of the student learning outcomes have been modified throughout the years to reflect contemporary jargon, the goals and student learning outcomes for the course have basically remained the same since the course was first offered. The team project is one of the course requirements. All students are grouped into teams, and the number of team members for each team varied according to student enrollment, ranging 3 to 8 . The students focus solely on the team project, after the initial course requirements have been completed, and for the second half of the term.

\section{Data Collection Tool}

The data for this study was collected using the Individual Contributions Form (see Appendix A), a confidential questionnaire created by one of the researchers. The Form was offered in two file formats: .pdf and .doc. Students had the option of submitting the Form via e-mail, via Fax, or as a hard copy. 


\section{Data Collection Procedure}

The Individual Contributions Form was collected from individual students after all other assignments had been completed. The Form asked students to consider each team member's contributions to all aspects of the team's work, including meetings, documents, and presentations, beginning with the formation of the team and ending with the adjournment of the team.

\section{Data Analysis Plan}

All Individual Contributions Forms collected since 2006 were included in this study. A total of 40 teams' Individual Contributions Forms from 191 students were entered into an electronic spreadsheet for analysis. Students' perceptions about their team members' contributions to the team project were compared to students' perceptions from other teams. The following coding criteria were adopted for this study:

A. Equal distribution: All team members scored each of their team members' contributions the same.

B. Small distribution: Small distribution was coded according to the narrow range of scores within teams as follows:

i. More than two-thirds of the team members scored the members of their team using less than a 3-point difference between the highest score and the lowest score

ii. more than two-thirds of the team members scored one team member higher than the others, but scored the other members the same or similarly; however, the difference was less than 5 points.

C. Large distribution: Large distribution was coded according to the wider range of scores within teams as follows:

i. More than two-thirds of the team members scored the members of their team with more than a 10-point difference between the highest score and the lowest score

ii. more than two-thirds of the team members scored one or more team members lower than the others, but scored the other members the same or similarly.

\section{RESULTS}

The first research question was concerned with the number of teams in which all team members agree that there was equal contribution. Four out of the 40 teams scored all team members' contributions to the team projects the same. Ten percent of the teams agreed that the team members contributed equally to the team projects.

The second research question dealt with the number of teams in which there is a small range of scores within the team. Eleven out of the 40 teams scored most team members' contributions to the team projects within a smaller range of difference in points, less than 3 points, or scored most team members the same with one team member receiving more points for contributing more to the team projects. Twenty-seven and a half percent of the teams agreed that team members' contributions were almost equal or similar without exceptions.

The third research question examined the larger range of distribution among the scores presented in the Individual Contributions Forms. A two-step analysis was used to answer this research question. First, the teams for which there was a large range between scores within the team were identified. In total, 16 out of the 40 teams were coded as large distribution. More than two-thirds of the team members teamwide reported noticeable discrepancies in contributions to the team projects with a range of 10 or more points among the team members. This number comprises 40 percent of the total. The widest range within a team was 21 points with the highest number of points awarded being 25 points and the lowest number 4 points. Variances in other teams coded as having a large distribution showed ranges from 5.5 points to 20 points. 


\section{CONCLUSIONS}

Overall, Tarricone and Luca's (2002) six attributes needed for effective teamwork were inferred. There appears to have been demonstrated a commitment to team success and shared goals, interdependence, development of interpersonal skills, the presence of open communication and positive feedback, appropriate team compositions, and commitment to team processes, leadership and accountability. This claim is further bolstered by the fact that the instructor has only met with 6 individual students since 2006, and with only 2 entire teams since 2006 regarding serious discrepancies among the distribution of scores reported on the Individual Contributions Form. Thus, the contention is that the role of the Individual Contributions Form worked as intended. Future studies of this nature need to enhance the objectivity associated with identifying the point at which the instructor feels the need to mediate between the team members. Further, while the organization of this college course in which the data was collected implemented Johnson, Johnson, and Smith's (2006) strategies for cooperative learning, future studies of this nature should consider additional ways to verify the effectiveness of the instructional strategies that emphasize: a) creating interdependence, b) devoting time for developing teamwork skills, and c) cultivating an atmosphere of individual accountability. The purpose of the team assignment was to foster collaborative learning through equal contributions among individuals while working as a team. This study served as a baseline for subsequent research about the patterns of student perceptions of contributions of other team members during a group project.

\section{REFERENCES}

Adams, H. P., \& Dickey, F. G. (1953). Basic principles of supervision. New York: American Book Company.

Branch, R., \& Chae, B. (2016). Genuine student-centered learning. Open Education Research, Special Issue: Innovative Applications of Educational Technology: Reflections and Prospects, 22(1), 1517.

Johnson, D. W., Johnson, R. T., \& Smith, K. A. (2006). Active learning: Cooperation in the college classroom (3rd ed.). Edina, MN: Interaction Book Company.

Miles, M. B., Huberman, A. M., \& Saldaña, J. (2014). Qualitative data analysis: A methods sourcebook (3rd ed.). SAGE Publications, Inc.

Tarricone, P., \& Luca, J. (2002). Successful teamwork: A case study. Proceedings of the $25^{\text {th }}$ HERDSA Annual Conference: Quality Conversations (pp. 640-646). Perth, Western Australia: Higher Education Research and Development Society of Australasia. 


\section{APPENDIX}

\section{INDIVIDUAL CONTRIBUTIONS FORM}

\section{DATE:}

\section{Individual Contributions}

This is a confidential survey of the contributions of the members of your team, including you. This takes into account each team member's contributions to all aspects of the team's work, including, but not limited to, meetings, documents, and presentations. The purpose of this confidential survey is to assist me, as the course instructor, in validating your final grade. You are required to complete this survey after considering all of the team's work beginning the time the team was formed until the time the final version of the project was submitted for a grade.

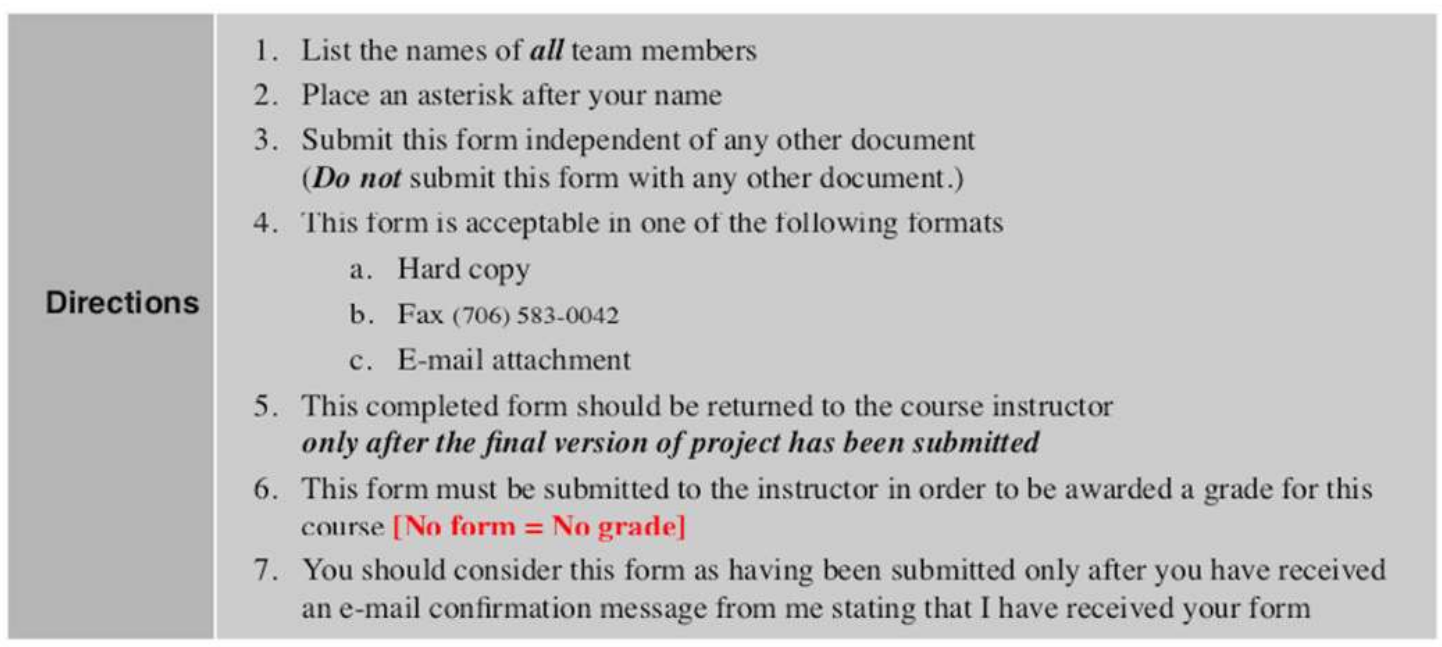

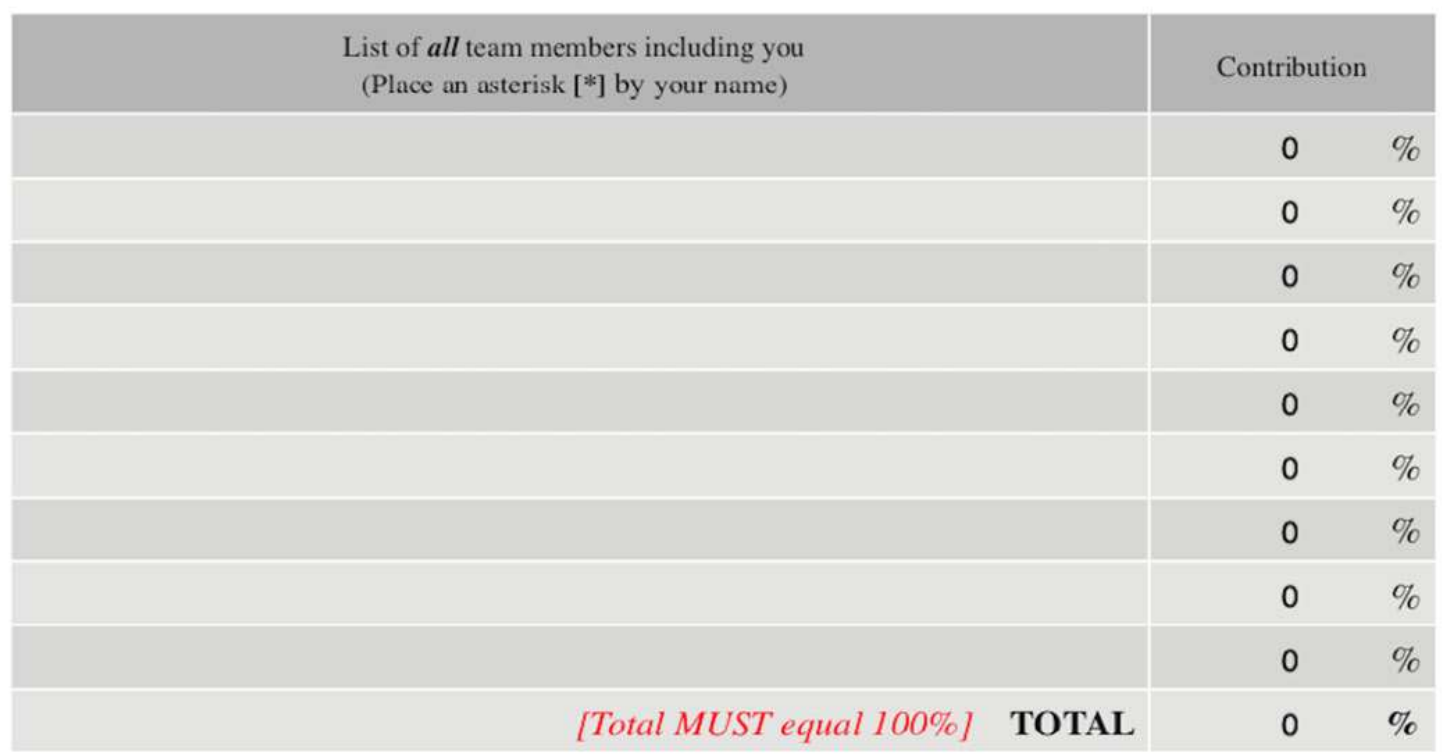

\section{Reset Print E-mail}

